\title{
Evaluation of atopy among mouth-breathing pediatric patients referred for treatment to a tertiary care center
}

\author{
Juliana R. C. Barros, ${ }^{1}$ Helena M. G. Becker, ${ }^{2}$ Jorge A. Pinto $^{3}$
}

\begin{abstract}
Objective: A mouth breather is someone who uses his/her oral cavity as main airway during breathing. This is a syndrome with several etiologies, but allergic rhinitis plays a key role due to its high prevalence. The aim of this study was to assess the presence of atopy among mouth-breathing patients referred to a tertiary care center in the metropolitan region of Belo Horizonte, Brazil.

Methods: Cross-sectional, descriptive study carried out at Hospital das Clínicas of Universidade Federal de Minas Gerais. Patients aged 2 to 12 years, admitted between November 2002 and April 2004, were included. Parents or surrogates completed a comprehensive questionnaire, and patients were submitted to a skin test for inhalant allergens. A total of 140 patients participated in the study. Those with a positive result for at least one allergen were regarded as atopic. The statistical analyses were made using SPSS, with univariate analyses followed by logistic regression.

Results: Of 140 patients, $44.3 \%(62 / 140)$ obtained positive results on the allergic test. Mites were the most predominant allergens, with a positive rate of $100 \%$ among atopic patients. In the multivariate analysis, atopy was significantly associated with the male sex $(p=0.05)$, presence of asthma $(p=0.014)$, lower number of people sleeping in the same room with the patient $(p=0.005)$, absence of passive smoking $(p=0.005)$ and absence of sleep apnea $(p=0.003)$.

Conclusion: The high prevalence of positive results on the allergic test highlights the importance of allergologic investigation in mouth-breathers, since allergy has specific treatments that may reduce morbidity in these patients when properly used.
\end{abstract}

J Pediatr (Rio J). 2006;82(6):458-64: Atopy, allergic rhinitis, mouth-breathers, allergen, dust mites.

\section{Introduction}

A mouth-breather is someone who replaces nasal breathing (correct breathing) with mouth-breathing or with a combined pattern ${ }^{1-3}$ for longer than 6 months. 4

Mouth-breathing results from several underlying disorders. ${ }^{2,3}$ It may result from mechanical factors (septal deviation, adenotonsillar hyperplasia), inflammatory diseases (allergic rhinitis), congenital malformations with craniofacial deformities, tumor lesions, among others. ${ }^{1,4}$

1. Mestre em Pediatria, Universidade Federal de Minas Gerais (UFMG), Belo Horizonte, MG, Brasil.

2. Doutora. Professora adjunta, Departamento de Oftalmologia e Otorrinolaringologia, Faculdade de Medicina, UFMG, Belo Horizonte, MG, Brasil.

3. Doutor. Professor adjunto, coordenador, Serviço de Alergia e Imunologia, Departamento de Pediatria, Faculdade de Medicina, UFMG, Belo Horizonte, MG, Brasil.

Manuscript received Mar 30 2006, accepted for publication Aug 162006

Suggested citation: Barros JR, Becker HM, Pinto JA. Evaluation of atopy among mouth-breathing pediatric patients referred for treatment to a tertiary care center. J Pediatr (Rio J). 2006;82:458-64.
Among inflammatory disorders, allergic rhinitis plays a key role, since it affects approximately 10 to $30 \%$ of the general population, ${ }^{1}$ and its incidence has been increasing in the last decades all over the world. 5,6

The aim of this study was to assess the presence of atopy among mouth-breathing patients referred to a tertiary care center in the metropolitan region of Belo Horizonte, Brazil, and to determine the prevalence and sensitization to aeroallergens, as well as to identify clinical and laboratory factors related to the presence of atopy in these patients.

\section{Methods}

This was a cross-sectional descriptive study ${ }^{7}$ carried out at the Outpatient Clinic for Mouth-Breathers, belonging to Hospital das Clínicas of Universidade Federal de Minas Gerais (HC/UFMG), in Belo Horizonte. All patients treated between November 2002 and April 2004 who met the inclusion criteria were assessed. 
Patients aged 2 to 12 years were included in the study. All of them complained of mouth-breathing and were referred to the Outpatient Clinic for Mouth-Breathers by different professionals. Parents or surrogates signed an informed consent form.

We excluded all patients who used drugs that could compromise the reliability of the skin test (ST) for inhalant allergens, such antihistamines, tricyclic antidepressants and corticosteroids, for a variable time according to the drug used. ${ }^{8}$ We also excluded patients with skin lesions that did not allow performing the ST, 8 and the refusal of parents or surrogates to participate in the study was an exclusion criterion.

Patients with mouth-breathing problems were referred to this outpatient clinic and assessed in one single day by a multidisciplinary team that consisted of an otolaryngologist (with the use of fiber-optic nasolaryngoscopy), allergologist, orthodontist and speech therapist.

Fiber-optic nasolaryngoscopy is a dynamic way of looking into the upper airways that allows detecting different etiologies of mouth-breathing and the degree of airway obstruction. It is a quick and simple method that can be performed at any age. ${ }^{1,2}$

The allergologic assessment included a structured medical interview, physical examination and ST, following the standard volar forearm skin prick method. ${ }^{8}$ The data obtained from the allergologic assessment and from fiberoptic nasolaryngoscopy were used in the present study.

In the allergologic anamnesis, three or more physiciandiagnosed bronchospasm episodes, the latter of which over the age of 2 years, were regarded as positive history of asthma. This definition was used because it is known that most wheezing episodes during the first two years of life result from the anatomy of the airways, associated with viral infections, which is a hindrance to diagnosis in this age group. ${ }^{9}$

A standard score was used for nasal symptoms. ${ }^{10,11}$ This score ranges from 0 to 3 in increasing order, according to the severity of the following symptoms: rhinorrhea, sneezing/itching, retronasal discharge and nasal obstruction, totaling 12 points on the general score.

History suggestive of allergic conjunctivitis was characterized by the presence of eye itching, hyperemia or tearing eyes on at least three occasions, after contact with a specific allergen and without any relationship with infectious processes. Atopic dermatitis was suggested by the history of chronic, pruriginous and recurrent dermatitis, with typical distribution and morphology of lesions. 12

For family history of atopy, parents were assessed as to the current or past presence of symptoms suggestive of asthma, allergic rhinitis, allergic conjunctivitis or atopic dermatitis.
The ST used extracts from the International Pharmaceutical Immunology do Brasil (IPI-ASAC BRASIL). Some of these extracts are standardized in biological units $(B U)$, while others in protein nitrogen units (PNU). The following extracts were used: Blomia tropicalis $37,650 \mathrm{BU} / \mathrm{mL}$, Dermatophagoides pteronyssinus 58,500 BU/mL, Dermatophagoides farinae 20,175 BU/mL, Alternaria alternata 63,600 BU/mL, Aspergillus fumigatus $10,000 \mathrm{PNU} / \mathrm{mL}$, Penicillium notatum 10,000 $\mathrm{PNU} / \mathrm{mL}$, Felis domesticus 94,500 $\mathrm{BU} / \mathrm{mL}$, Canis familiaris 10,000 $\mathrm{PNU} / \mathrm{mL}$, Periplaneta americana 5,000 PNU/mL and Blatella germanica 5,000 $\mathrm{PNU} / \mathrm{mL}$. A positive control (histamine $50 \%$ plus saline solution and phenol $0.4 \%$ ) and a negative control (50\% of glycerine, $50 \%$ of saline solution and phenol $0.4 \%$ ) were used.

The ST result was obtained quantitatively by calculating the arithmetic means of the largest papule diameters and orthogonal diameters in their medians. Reading was made 15 minutes after puncture, and all tests whose papules had a mean diameter at least $3 \mathrm{~mm}$ larger than the negative control were regarded as positive. ${ }^{8,13}$

Whole blood count, total serum immunoglobulin $\mathrm{E}$ (IgE) determination by chemiluminescence and three samples from the parasitological stool test were also obtained.

The atopic group was characterized by the presence of mouth-breathing associated with positive ST for a given inhalant. The nonatopic group consisted of mouth-breathing patients with ST negative for all inhalants tested.

This study was approved by the Research Ethics Committee of UFMG, and all parents or surrogates signed an informed consent form.

Statistical analyses were made using SPSS, version 11.5. For comparison of the characteristics between groups, we used the chi-square test for dichotomic variables and Mann-Whitney's nonparametric test for quantitative variables with non-normal distribution. The nutritional assessment was made by the Epinut module of Epi-Info, whose reference standard for children is recommended by the World Health Organization, where the 10th percentile was regarded as cutoff point for weight and height versus age. ${ }^{14}$

The multivariate analysis through forward stepwise multiple logistic regression determined the risk factors associated with positive ST results. The variables selected for this model were those with a $p$ value less than 0.20 and/or those that were biologically feasible in the univariate analysis.

All $p$ values less than or equal to 0.05 were statistically significant. 


\section{Results}

A total of 140 patients participated in the study. Of these, $73(52.1 \%)$ were male. Age ranged from 2.1 to 12.7 years, with a median of 6.1 years. Age at the onset of nasal symptoms corresponded to 0 to 9 years, with a median of 1.5 years. A total of $127(90.7 \%)$ patients were classified as having persistent nasal symptoms. ${ }^{6,15}$ The median family income was around 2.2 minimum wages, with a range from 0 to 12.5 .

The ST was performed on all participants and no adverse event resulted from its application. The test was positive in 62 patients $(44.3 \%)$. Note that $81(57.9 \%)$ patients were referred by an otolaryngologist, 39 (27.9\%) by a pediatrician, nine $(6.4 \%)$ by a pulmonologist, six $(4.3 \%)$ by a speech therapist and four $(2.9 \%)$ by an allergologist; in one patient $(0.7 \%)$, information about the referral was not available. There were no remarkable differences in the prevalence of positive ST results among the various subgroups of patients.

Mites were the most prevalent allergens ( 62 patients, $100 \%$ of atopic ones); 60 (96.8\%) of these patients were positive for Dermatophagoides pteronyssinus, 53 (85.5\%) were positive for Dermatophagoides farinae, and 40 $(64.5 \%)$ for Blomia tropicalis. Note that 37 patients $(59.7 \%)$ were simultaneously positive for the three mites tested, and only eight (12.9\%) had a positive ST for only one of the three mites tested.

The percentage of positive results for the other allergens was lower than that obtained for mites (17 patients, $27.4 \%$ of atopic ones). Five patients ( $8.1 \%$ ) tested positive for Canis familiaris, three (4.8\%) for Felis domesticus, three (4.8\%) for Blatella germanica, four (6.5\%) for Periplaneta americana, one for Aspergillus fumigatus $(1.6 \%)$ and another one for Penicillium notatum (1.6\%). No patients tested positive for Alternaria alternata. All these patients concomitantly had positive results for mites.

The following results were obtained by comparing the atopic (positive) and nonatopic (negative) groups:

Median age in the atopic group was 7.1 years versus 5.3 years in the nonatopic group $(p=0.004)$. No statistically significant difference was observed between the two groups with regard to sex $(p=0.155)$, age at the onset of nasal symptoms $(p=0.177)$ and family income $(p=0.257)$.

As to the nutritional aspect, there was no significant difference between groups in terms of weight and height in relation to age ( $p=0.995$ for weight and $p=0.0552$ for height).

The other variables and their significance level are shown in Tables 1 and 2 .

Although all patients were supposed to do the lab tests, only 96 turned up for blood collection for total serum IgE determination. The median among atopic patients amounted to $355.5 \mathrm{IU} / \mathrm{mL}$, with a range from 31.4 to over $2,000 \mathrm{IU} / \mathrm{mL}$, compared to a median of only $89.4 \mathrm{IU} / \mathrm{mL}$ among nonatopic patients, ranging from 5.3 to over $2,000 \mathrm{IU} / \mathrm{mL}(p<0.001)$. The whole blood count, performed in 107 patients, revealed a median eosinophil count of 493 and 300 cells $/ \mathrm{mm}^{3}$ in atopic and nonatopic patients, respectively $(p=0.007)$.

Table 1 - Association between atopy and clinical manifestations of allergic diseases

\begin{tabular}{|c|c|c|c|c|}
\hline Variable & Atopic group & Nonatopic group & OR (95\%CI) & $\mathbf{p}$ \\
\hline \multicolumn{5}{|l|}{ Quality of nasal symptoms } \\
\hline Rhinorrhea & $23 / 62(37.1 \%)$ & $29 / 78(37.2 \%)$ & $1(0.5-2.1)$ & 1 \\
\hline Sneezing & $45 / 62(72.6 \%)$ & $42 / 78(53.9 \%)$ & $2.3(1.0-5.0)$ & 0.04 \\
\hline Itchy nose & $51 / 62(82.3 \%)$ & $51 / 78(65.4 \%)$ & $2.5(1.0-6.0)$ & 0.04 \\
\hline Discharge (retronasal) & $30 / 62(48.4 \%)$ & $41 / 78(52.6 \%)$ & $0.9(0.4-1.8)$ & 0.75 \\
\hline Obstruction & $60 / 62(96.8 \%)$ & $76 / 78(97.4 \%)$ & $0.8(0.1-8.3)$ & 1 \\
\hline \multicolumn{5}{|l|}{ Other important complaints } \\
\hline Snoring & $59 / 62(95.2 \%)$ & $71 / 77(92.2 \%)$ & $1.7(0.3-8.9)$ & 0.73 \\
\hline Apnea & $28 / 61(45.9 \%)$ & $50 / 77(65.0 \%)$ & $0.5(0.2-1.0)$ & 0.04 \\
\hline \multicolumn{5}{|l|}{ Other allergic disorders } \\
\hline Conjunctivitis & $35 / 62(56.5 \%)$ & $32 / 78(41.0 \%)$ & $1.9(0.9-3.9)$ & 0.1 \\
\hline Asthma & $30 / 62(48.4 \%)$ & $16 / 76(21.1 \%)$ & $3.5(1.6-8.0)$ & 0.001 \\
\hline Atopic dermatitis & $6 / 62(9.7 \%)$ & $6 / 78(7.7 \%)$ & $1.3(0.3-4.9)$ & 0.91 \\
\hline Urticaria & $17 / 62(27.4 \%)$ & $15 / 78(19.2 \%)$ & $1.6(0.7-3.8)$ & 0.35 \\
\hline Angioedema & $8 / 62(12.9 \%)$ & $3 / 78(3.9 \%)$ & $3.7(0.8-18.8)$ & 0.06 \\
\hline
\end{tabular}

$95 \% \mathrm{Cl}=95 \%$ confidence interval; OR = odds ratio 
Table 2 - Association between atopy and conditions implicated in the occurrence of allergic diseases

\begin{tabular}{|c|c|c|c|c|}
\hline Variable & Atopic group & Nonatopic group & OR $(95 \% \mathrm{CI})$ & $\mathbf{p}$ \\
\hline Maternal smoking during pregnancy & $8 / 62(12.9 \%)$ & $11 / 72(15.3 \%)$ & $0.8(0.3-2.4)$ & 0.89 \\
\hline Passive smoking & $20 / 62(32.3 \%)$ & $37 / 78(47.4 \%)$ & $0.5(0.3-1.1)$ & 0.1 \\
\hline Atopic mother & $34 / 61(55.7 \%)$ & $37 / 76(48.7 \%)$ & $1.3(0.6-2.8)$ & 0.52 \\
\hline Atopic father & $25 / 58(43.1 \%)$ & $18 / 72(25.0 \%)$ & $2.3(1.0-5.2)$ & 0.05 \\
\hline Pets at home & $40 / 62(64.5 \%)$ & $45 / 78(57.7 \%)$ & $1.3(0.6-2.8)$ & 0.52 \\
\hline Use of a plastic mattress cover & $8 / 62(12.9 \%)$ & $11 / 78(14.1 \%)$ & $0.9(0.3-2.7)$ & 1 \\
\hline Type of dwelling = house & $56 / 62(90.3 \%)$ & $76 / 78(97.4 \%)$ & $0.3(0.0-1.4)$ & 0.14 \\
\hline $\begin{array}{l}\text { Number of people sleeping } \\
\text { in the same room with a child } \\
\text { ( } 2 \text { or less) }\end{array}$ & $44 / 62(71.0 \%)$ & $30 / 78(38.5 \%)$ & $3.9(1.8-8.6)$ & 0.0003 \\
\hline Variable & $\begin{array}{l}\text { Positive ST } \\
\text { median in } \mathbf{m m} \\
\quad \text { (range) }\end{array}$ & $\begin{array}{l}\text { Negative ST } \\
\text { median in } \mathbf{m m} \\
\quad \text { (range) }\end{array}$ & $\mathbf{p}$ & \\
\hline Length of breastfeeding (months) & $6(0-60)$ & $6(0-48)$ & 0.46 & \\
\hline $\begin{array}{l}\text { Age at the introduction } \\
\text { of the first milk formula (months) }\end{array}$ & $3.5(0-60)$ & $4(0-48)$ & 0.25 & \\
\hline
\end{tabular}

$95 \% \mathrm{Cl}=95 \%$ confidence interval; $\mathrm{OR}=$ odds ratio.

Parasitological stool examination was obtained from 101 patients, and was positive in $52.1 \%$ of cases. Ascaris lumbricoides, Giardia lamblia and Entamoeba histolytica were the parasites found. The positive result for the parasitological stool test did not differ between the analyzed groups ( $p=0.48$ ).

The statistically significant variables after the multivariate analysis can be seen in Table 3 .

According to the fiber-optic laryngoscopy results, only 18 patients $(12.9 \%)$ were classified as functional mouthbreathers, i.e., without any anatomical problems that could hinder the appropriate air inflow through the upper airways.

As to organic mouth-breathers, $86(70.5 \%)$ required surgery, either in isolation or combined with clinical treatment. Adenoidectomy alone or in conjunction with tonsillectomy was performed in 85 patients, indicating that adenotonsillar hyperplasia is the major cause of mouth-breathing in our sample. One patient was submitted to choanal atresia repair. Surgery was indicated in $45.2 \%$ of atopic patients (28 patients) and in $73.1 \%$ of nonatopic ones (57 patients) $(p=0.001)$.

Table 3 - Multiple logistic regression analysis between independent variables and positive skin test results

\begin{tabular}{lcc}
\hline Variables & OR (95\%CI) & $\mathbf{p}$ \\
\hline Male sex & $2.8(1.0-7.9)$ & 0.05 \\
Personal history of asthma & $4.0(1.3-11.9)$ & 0.01 \\
Absence of passive smoking & $4.7(1.6-14.1)$ & 0.005 \\
Presence of 1 or 2 people sleeping & $4.4(1.6-12.3)$ & 0.005 \\
in the same room with the child & & \\
Absence of sleep apnea & $5.7(1.8-18.2)$ & 0.003
\end{tabular}

$95 \% \mathrm{Cl}=95 \%$ confidence interval; $\mathrm{OR}=$ odds ratio. 


\section{Discussion}

Mouth-breathing is an important issue in pediatrics, requiring proper management of its determining factors so that morbidity can be reduced. ${ }^{1-3}$

Although most authors agree with the definition of mouth-breathers, there is no consensus about the best way to identify them. Reports by parents or surrogates about the presence of snoring, open-mouth habits, nasal obstruction and excess salivation should always be taken into account by health care providers. ${ }^{2}$ Currently, rhinomanometry has been the method for the diagnosis and quantification of mouth-breathers, since it assesses nasal resistance. 10,11 However, it is seldom used in medical practice due to its prohibitive cost. In the present study, we assessed patients with mouth-breathing problems.

Adenotonsillar hyperplasia was the major reason for mouth-breathing in our sample. Moreover, $44.3 \%$ of patients had a positive ST for some inhalant, compared to 10 to $30 \%$ of the general population. ${ }^{1}$ The lack of remarkable differences in the prevalence of positive ST results according to the type of referral reduces the possibility for selection bias. These results are consistent with the literature, which points out adenotonsillar hyperplasia and allergic rhinitis, either alone or in combination, as important factors in the etiology of mouth-breathing. 2,3,15

The skin prick test is quick, inexpensive and easy to perform and standardize, being an important tool in the diagnosis of IgE-mediated sensitivity. $5,6,8$ Its results are not reliable in children younger than 2 years, ${ }^{8}$ which explains the selection of patients older than 2 years in our study.

Geller $^{16}$ conducted a study to assess sensitivity to mites in Rio de Janeiro by submitting 700 patients with asthma and/or rhinitis older than 2 years to skin tests for seven different mites. His conclusion was that $D$. pteronyssinus, $B$. tropicalis and $D$. farinae are enough to establish the diagnosis of mite sensitization. 16

In the present study, the ST included three types of mites, in addition to allergens derived from dogs, cats, and cockroaches. As expected, there was a preponderance of mites (especially $D$. pteronyssinus and $D$. farinae), whereas the other allergens had a lower percentage of positive results. This result concurs with that of other studies carried out in the state of Minas Gerais, Brazil.13,17

Simultaneous sensitization to the three types of mites was quite frequent in our study, which may mean crossreaction or specific sensitization. ${ }^{13}$

Sensitization to cockroaches has been widely investigated nowadays, especially in populations with a low socioeconomic level. There is an estimate that $55 \%$ of patients with asthma and/or allergic rhinitis living in São Paulo or Ribeirão Preto tested positive for Blatella germanica and/or Periplaneta americana. ${ }^{18-20}$
By comparing atopic and nonatopic patients as to the quality and intensity of clinical symptoms, risk factors associated with atopy, or even lab tests, the multivariate analysis revealed that being male and having asthma were significantly associated with atopy. Furthermore, atopic patients had a significantly lower number of smokers at home and a smaller number of people sleeping in the same room. There was a negative statistically significant correlation between positive skin test results and apnea.

It should be underscored that the median age in the atopic group is higher than that in the nonatopic one. This suggests a higher prevalence of atopy in older children. However, age has no statistical significance when adjusted in the multivariate model, suggesting that this variable is not so important in the presence of other variables.

Being a male child has been regarded by many authors as a risk factor for allergic diseases. In puberty, the disease affects both sexes equally. ${ }^{21}$

The predominant current definition of a single systemic allergic disorder with several target organs explains the concomitant occurrence of diseases such as allergic rhinitis, asthma and atopic dermatitis. All these disorders have pathophysiological mechanisms in common, which make them closely related. 22,23

The presence of asthma was strongly associated with atopic mouth-breathing patients in this study. This result is in agreement with the literature, since approximately $80 \%$ of asthmatic children have a positive ST, and between 30 and $80 \%$ have nasal symptoms as well. The association between asthma and allergic rhinitis is so important that some authors would rather use the term "united airway disease." 6

No significant association was found between atopy and other allergic disorders, such as allergic conjunctivitis, atopic dermatitis, urticaria and angioedema. Urticaria had a high prevalence among nonatopic patients as well. This may have occurred due the limitation of the diagnostic method, since the data are based on the history obtained from family members. Also, viral infections and food allergens are likely to play a role in the etiopathogenesis of these diseases. 12,24

In the present study, we observed a high prevalence of sleep apnea in mouth-breathing patients (over $50 \%$ ), which differs from that cited in the literature. ${ }^{25}$ It is common knowledge that parent's observations are not accurate in the diagnosis of sleep apnea, ${ }^{25}$ and that this information can be overestimated. Another possible explanation would be a selection bias, with more severely ill patients being referred to tertiary care.

On the other hand, one should also consider the negative statistically significant association between positive ST and apnea. Very likely, this finding reflects the larger incidence of higher-grade adenotonsillar 
hyperplasia in the nonatopic group, which is the major cause of apnea in this age group. The higher percentage of surgical indication in the nonatopic group observed in this study confirms this hypothesis. A recent study assessing 630 children with allergic rhinitis showed that the presence of adenoid hypertrophy is a remarkable risk factor for sleep apnea. 26

Much controversy has arisen over the risk factors for the development of atopy. It has been postulated that genetic and environmental factors in the first years of life can determine the type of immune response in the future. 21,27

The type of feeding in the first months of life has received special attention, and several studies were carried out, but with discrepant results. A recent meta-analysis was carried out to establish the relationship between exclusive breastfeeding for 3 months after birth and the presence of allergic rhinitis. ${ }^{28}$ A statistically nonsignificant association was found, indicating the need for further studies. ${ }^{28}$

As to the family history of atopy, most authors believe that maternal (instead of paternal) allergy is a risk factor for asthma and allergic rhinitis in children. ${ }^{21}$ In our study, paternal and maternal histories of atopy were not significantly associated with positive ST results.

Determining the etiology of atopy is complex due to the interaction of several factors. Even though these factors have been extensively investigated in several studies on the subject, their importance still needs to be confirmed by further studies. ${ }^{21}$

Serum IgE levels and eosinophil count have a secondary importance in the diagnosis of atopy in this study, since neither of them was significant after the multivariate analysis. Levels of specific IgE antibodies to inhalant allergens, albeit more reliable for the diagnosis of atopy, ${ }^{5}$ were not determined in this study due to the high cost of this test.

Control measures against inhalant allergens, although controversial, 29,30 are recommended on a routine basis by consensuses. ${ }^{5,6}$ Only $13.6 \%$ of mouth-breathers in our study used mattress and pillow covers. As this is an important measure, 5,6 it was recommended for all those patients with a positive ST. On the other hand, the fact that atopic patients had a significantly lower number of smokers at home and a smaller number of people sleeping in the same room, compared to nonatopic patients, may represent intervention measures by the family.

Mouth-breathers constitute a heterogeneous group, so the importance of a multidisciplinary team for their proper management should be emphasized. ${ }^{1}$

In conclusion, the high prevalence of atopy observed in this study highlights the importance of allergologic assessment in mouth-breathing patients, since allergic disorders have specific treatments, which may improve the management of mouth-breathers. ${ }^{5}$

\section{References}

1. Becker HMG, Guimarães RES, Pinto JA, Vasconcellos MC. Respirador bucal. In: Leão E, Correa EJ, Mota JAC, Viana MB. Pediatria ambulatorial. Belo Horizonte: Coopmed; 2005. p. 487-93.

2. Saffer M. Mouth breather. In: II IAPO/Ifos pediatric ent manual: 166-77.

3. Motonaga SM, Berti LC, Anselmo-Lima WT. Respiração bucal: causas e alterações no sistema estomatognático. Rev Bras Otorrinolaringol. 2000;66:373-9.

4. Rizzo MC. O respirador bucal. In: Naspitz C. Alergias respiratórias. São Paulo: Vivali; 2003. p. 98-110.

5. van Cauwenberge P, Bachert C, Passalacqua G, Bousquet J, Canonica GW, et al. Consensus statement on the treatment of allergic rhinitis. European Academy of Allergology and Clinical Immunology. Allergy. 2000;55:116-34.

6. ARIA Brasil. Manejo da rinite alérgica e seu impacto na asma Guia de bolso. Salvador: ARIA; 2002.

7. Gordis L. Estudos caso-controle e transversal. In: Gordis L. Epidemiologia. Rio de Janeiro: Revinter; 2000. p 143-57.

8. EAACI. Position paper: allergen standardization and skin tests. The European Academy of Allergology and Clinical Immunology. Allergy. 1993;48 Suppl 14:48-82.

9. Martinez FD, Wright L, Taussig LM, et al. Asthma and wheezing in the first 6 years of life. N Engl J Med. 1995;332:133-8.

10. Meltzer EO. Evaluating rhinitis: Clinical, rhinomanometric and cytologic assessments. J Allergy Clin Immunol. 1988;82:900-8.

11. Welch MJ, Meltzer EO, Orgel HA, Kemp JP. Assessment of the correlation of rhinometry with the symptoms and signs of allergic rhinitis in children. Ann Allergy. 1985;55:577-9.

12. Castro, APB. Dermatite atópica. In: Grumach ASG. Alergia e Imunologia na Infância e Adolescência. São Paulo: Atheneu; 2001. p.185-201.

13. Marques MC, Pinto JA, Greco DB. Sensibilização a aeroalérgenos em crianças e adolescentes atópicos em Belo Horizonte, MG: comparação da estimativa de IgE específica "in vivo" versus "in vitro". Rev Bras Alergia Imunopatol. 2001;24:22-32.

14. Goulart, EMA. Metodologia e informática na pesquisa médica. Belo Horizonte: Copyright; 2000.

15. Rizzo MC. O respirador bucal. In: Naspitz CK. Alergias respiratórias. São Paulo: Vivali; 2003. p. 97-110.

16. Geller M. Alergia aos ácaros no Rio de Janeiro. Análise prospectiva em 700 pacientes com asma e (ou) rinite. J Bras Med. 1996;71:164-8.

17. Sopelete MC, Silva D, Arruda K, Chapman MD, Taketomi EA. Dermatophagoides farinae and Dermatophagoides pteronyssinus allergen exposure among subjects living in Uberlândia, Brasil. Int Arch Allergy Immunol. 2000;122:257-63.

18. Tobias KRC, Ferriani VPL, Chapman MD, Arruda K. Exposure to indoor allergens in homes of patients with asthma and/or rhinitis in southeast Brazil: effect of mattress and pillow covers on mite allergen levels. Int Arch Allergy Immunol. 2004;133:365-70.

19. Santos ABR, Chapman MD, Aalberse RC, Vailes LD, Ferriani VPL, Oliver $C$, et al. Cockroach allergens and asthma in Brazil: Identification of tropomyosin as a major allergen with potential cross-reactivity with mite and shrimp allergens. J Allergy Clin Immunol. 1999;104:329-37.

20. Rosenstreich DL, Eggleston P, Kattan M, Baker D, Slavin RG, Gergen $P$, et al. The role of cockroach allergy and exposure to cockroach allergen in causing morbidity among inner-city children with asthma. N Engl J Med. 1997;336:1356-63.

21. Arshad SH, Stevens M, Hide D. The effect of genetic and environmental factors on the prevalence of allergic disorders at the age of two years. Clin Exp Allergy. 1993;23:504-11.

22. Bousquet J. Allergy as a global problem: "Think globally, act globally". Allergy. 2002;57:661-2.

23. Chatkin MN, Menezes AMB. Prevalência e fatores de risco para asma em escolares de uma coorte no sul do Brasil. J Pediatr (Rio J). 2005;81:411-6.

24. Oliveira ZNP. Urticária. In: Grumach ASG. Alergia e imunologia na infância e adolescência. São Paulo: Atheneu; 2001. p.171-83. 
25. Schechter MS; Section on pediatric pulmonology, subcommittee on obstructive sleep apnea syndrome. Technical report: diagnosis and management of childhood obstructive sleep apnea syndrome. Pediatrics. 2002;109:e69.

26. Huang S, Giannoni C. The risk of adenoid hypertrophy in children with allergic rhinitis. Ann Allergy Asthma Immunol. 2001;87:350-5.

27. Correa JMM, Zuliani A. Imunidade relacionada à resposta alérgica no início da vida. J Pediatr (Rio J). 2001;77:441-6.

28. Bloch AM, Mimouni D, Mimouni M, Gdalevich M. Does breastfeeding protect against allergic rhinitis during childhood? A meta-analysis of prospective studies. Acta Pediatr. 2002;91: 275-9.

29. Terreehorst I, Hak E, Oosting AJ, Tempels-Pavlica Z, Monchy JGR, Bruijnzeel-Koomen CA, et al. Evaluation of impermeable covers for bedding in patients with allergic rhinitis. N Engl J Med. 2003;349:237-46.
30. Sheikh A, Hurwitz B. House dust mite avoidance measures for perennial allergic rhinitis: a systematic review of efficacy. $\mathrm{Br} \mathrm{J}$ Gen Pract. 2003;53:318-22.

Correspondence:

\section{Jorge A. Pinto}

Av. Alfredo Balena $190,4^{\circ}$ andar

CEP 30130-100 - Belo Horizonte, MG - Brazil

Tel.: + 55 (31) 3248.9822

Fax: +55 (31) 3273.0422

E-mail: jpinto@medicina.ufmg.br 